\title{
POR DENTRO E POR FORA: A SUBVERSÃO NA PRÁTICA
}

\section{BY INSIDE AND OUTSIDE: THE SUBVERSION IN PRACTICE}

\author{
Delphine Dulong*
}

Introdução

A influência das instituições sobre os atores é um postulado do senso comum erudito fundador desse campo de estudo. Em uma "comunidade" tão fragmentada quanto a dos pesquisadores que trabalham sobre as instituições, estamos de acordo ao menos neste ponto: as instituições têm uma capacidade assegurada - mesmo que variada de constranger o comportamento dos atores, contribuindo assim para a formação de suas preferências, para a construção de seus esquemas cognitivos e, mais amplamente, de sua identidade social. Essa constatação não deve, contudo, levar a subestimar as práticas desviantes. Pois, como mostrou Erving Goffman, elas existem até mesmo nas instituições totais, logo privativas de liberdade e/ou de identidade individual (GOFFMAN, 1968). Mais do que isso, essas práticas são, na realidade, inerentes à instituição. A definição de papéis e de regras institucionais se realiza, antes de tudo, na prática, assim como na ordem das representações. Por isso, jamais é fixa e perene. Privilegiar uma visão congelada é adotar um ponto de vista objetivista, que é também o ponto de vista daqueles que se proclamam guardiões da "verdade" da instituição. Ela é, na realidade, plural e comporta uma multiplicidade de práticas que estão longe de serem sempre ortodoxas, quer dizer, em conformidade às expectativas daqueles que a dirigem. Algumas dessas práticas são mesmo consideradas como subversivas à medi-

1. Texto originalmente publicado na coletânea: LAGROYE, J; OFFERLÉ, M. (Orgs.). Sociologie de l'institution. Paris: Belin, 2011. Tradução de Maurício Izelli Doré. Revisão de Igor Gastal Grill. Os editores da REPOCS e as organizadoras deste dossiê agradecem Delphine Dulong pela autorização para publicar versão em português neste periódico.

* Professora e pesquisadora na Université Paris 1 (Paris/FR). Participa do Centre Européen de Sociologie et de Science Politique (CESSP). E-mail: delphine.dulong@univ-paris1.fr 
da que elas põem em perigo a ordem estabelecida. Por isso, elas nos ensinam muito sobre o funcionamento concreto das instituições e, mais precisamente, sobre as condições do constrangimento que exercem sobre os atores. Condições essas que aparecem mais frequentemente como algo dado do que sociologicamente descrito. É essa dimensão da instituição que gostaríamos de esclarecer nessa contribuição, retomando a todo momento os diferentes níveis de análise que implicam o estudo de práticas e de condutas subversivas ${ }^{2}$. Veremos, assim, que esse tipo de prática é indissociável de um outro tipo: aquelas que consistem em validar ou, ao contrário, proibir as práticas dos atores institucionais, conferindo-lhes sentido. Veremos, em seguida, que se as propriedades dos atores informam sempre sobre suas práticas, as propriedades da instituição e da situação - ou seja, aquelas do contexto no qual se desenvolvem as práticas subversivas - parecem ainda mais esclarecedoras.

\section{0 sentido institucional das práticas}

Por se inscreverem nas lutas simbólicas pela defınição legítima da instituição e dos papéis a ela relacionados, a análise das práticas subversivas é, em primeiro lugar, indissociável da análise da atividade de etiquetagem, que consiste em conferir um sentido às práticas dos atores. Segundo Howard Becker, é preciso considerar que as práticas ditas subversivas não são nem o traço de uma personalidade singular ("subversiva”), nem o produto de uma disfunção social (como a anomia), mas muito mais o resultado de uma transação entre um grupo e um indivíduo que transgride uma norma
(BECKER, 1985, p. 33). Mais que um postulado, esse modo de apreender o objeto é uma regra de método necessária por múltiplas razões.

A primeira se deve a uma constatação muito simples: as práticas subversivas são frequentemente negadas, até mesmo ignoradas enquanto tais, pelos seus atores. Consideremos tudo o que se faz em nome da “modernização" de uma instituição: quer se trate de importar a lógica da economia liberal em instituições tradicionalmente assentadas na "cultura" do serviço público, ou da fundamentação de decisões da justiça menos a partir do direito do que por uma $e x$ pertise sociológica (ou por um registro político, a exemplo dos juízes italianos da operação mãos limpas). Essas práticas subversivas foram apresentadas pelos seus atores sob o registro da "modernização necessária" do Estado e da justiça. E não é ingenuidade - mas característico da sociologia compreensiva - pensar que essas práticas eram vividas pelos atores menos como um perigo do que como um benefício para a instituição. Adotar a postura do interacionismo simbólico no caso que nos ocupamos aqui, é, portanto, preservar, antes de mais nada, o princípio da neutralidade axiológica, caro a Max Weber, e se armar contra todo julgamento moral, que o objeto particularmente desperta.

Essa postura revela, além disso, forte poder heurístico quando temos uma instituição como categoria (e objeto) de análise. Uma vez que nos convida a dar atenção particular às atividades agonísticas de atribuição de sentido às condutas dos atores, ela nos fornece, em segundo lugar, os meios de compreender como a instituição,

2. Ao longo do artigo empregaremos o termo práticas subversivas à medida que o comportamento dos atores for intencionalmente subversivo e condutas quando não visam a subversão da instituição. 
ainda que (re)trabalhada sem trégua tanto do interior como do exterior, pode, apesar de tudo, conferir a si o caráter sagrado de um conjunto homogêneo, estável e quase imutável. Inicialmente, porque as táticas de denegação do caráter subversivo de uma ação - sendo elas frequentemente o produto daqueles que buscam legitimar suas condutas negando seu caráter perigoso ou nocivo para a instituição -, encontram-se também ao lado daqueles que têm interesse em que nada mude. 0 melhor exemplo, a esse respeito, é talvez aquele dos médicos dos manicômios estudados por Goffman ou ainda aqueles do império colonial ${ }^{3}$, que incansavelmente buscaram qualificar de "patológicos” os comportamentos desviantes que observavam - como a "fuga" de escravos, assim apresentada como a "doença negra”, "mal negro” por excelência (DORLIN, 2006) - a fim de limitar simbolicamente a dimensão subversiva daquilo que, do ponto de vista dos seus atores, era uma forma de resistência à opressão (ou, para retomar os termos de Goffman, uma forma de adaptação secundária à instituição) ${ }^{4}$. Os atores "subversivos", por sua vez, com o intuito de subverter a instituição, conscientemente ou não, têm frequentemente a tendência de justificar seu comportamento a partir dos registros clássicos de legitimação das insti- tuições, como a continuidade e/ou a tradição, esforçando-se em mostrar tudo o que há de compativel entre o que fazem e o que se supõe ser a própria "essência" da instituição. A “modernização” do Estado estará assim ligada aos valores mais essenciais do poder político (eficácia, transparência, etc.); aquela da instituição judiciária será justificada pelos princípios de equidade e de neutralidade que buscam conservar, etc. As práticas subversivas, apresentadas sob o registro da modernização ou de um retorno às origens, estarão sempre conectadas - com, é claro, mais ou menos sucesso - aos princípios fundadores e aos valores mais sagrados da instituição, garantindo, assim, essa presunção de continuidade, que está no princípio mesmo da noção de instituição.

Contudo, integrar essas lutas simbólicas na análise das práticas e condutas subversivas, signifıca também, como terceira razão, considerar que os comportamentos esperados não são imutáveis. Aqueles que ocupam uma posição de poder na instituição podem buscar, por razões que devem ser explicadas, mudá-las. Certas práticas, até então legítimas, podem assim, de um dia para outro, serem taxadas de "subversivas". Com efeito, à medida que o uso da batina e a missa em latim são deslegitimados pelo Concílio Vaticano II, serão excomungados todos aqueles

3. Pode-se também tomar como exemplo as acusações de bruxaria multiplicadas pela Igreja entre os séculos XVI e XVII. Como mostram os trabalhos de historiadores, 80\% das vítimas eram mulheres de classes populares cujo o comportamento emancipado tende a subverter as relações sociais tradicionais de gênero, seja por serem depositárias de um saber medicinal ancestral, vestirem-se como homem como Joana d'Arc, reivindicarem uma independência econômica ou simplesmente uma sexualidade. Ver, por exemplo: Muchembled (1979); Ginzburg (1993).

4. Segundo Goffman: “as adaptações secundárias representam para o indivíduo o meio de escapar ao papel e ao personagem que a instituição naturalmente lhe encarrega” (1968, p. 245). São práticas e/ou condutas desviantes que podem ser subversivas (ou "desintegradoras" como diz Goffman), à medida que seus atores buscam romper com o funcionamento da instituição; mas podem também estar "integradas" se seus autores aceitarem as estruturas institucionais existentes (cf. infra). Nesse caso, serão qualificadas simplesmente de desviantes ou de resistência. 
que se recusarem a tais mudanças em nome da tradição da Igreja Católica, como os integralistas católicos ${ }^{5}$ liderados por Mons. Lefebvre. Da mesma forma, quando as práticas policiais de controle das fraudes dos agentes de Seguridade Social ${ }^{6}$ são denunciadas, no final dos anos 1990, como sendo contrárias aos mais elementares direitos do homem, a direção do $\mathrm{CNAF}^{7}$ passa a impor aos seus agentes um novo código de ética. Desse modo, as práticas mais eficazes em matéria de luta contra fraudes (visitas domiciliares de madrugada sem aviso prévio, entrevistas com os filhos na saída da escola, etc.) tornam-se subversivas, pois suscetíveis, nesse novo contexto, de descreditarem a instituição ${ }^{8}$. Em tais casos, os mais desestabilizados não são aqueles que detêm o poder na instituição, mas aqueles acusados de perturbar seu funcionamento.

Isso significa dizer que as práticas e condutas subversivas não são sempre o que aqueles que assim as etiquetam dizem ser. É por isso que elas devem não somente estar conectadas às motivações dos seus atores, mas, talvez mais ainda, àquelas dos que, erigindo-se guardiões da "verdade" da instituição, denunciam as práticas e condutas como subversivas. Essa dupla perspectiva é tanto mais necessária à medida que cer- tas práticas ditas subversivas por seus atores podem não o ser para os guardiões da "verdade". Por exemplo, tomar a palavra em público, a fortiori no caso de uma mulher grávida, é com frequência vivido por mulheres políticas como uma forma de subversão, já que transgride a divisão sexual do trabalho. Mas à medida que a posição que ocupam as autoriza a assim fazer - quando são eleitas, em posição de porta-voz ou em uma posição de poder -, essa prática subversiva do ponto de vista das relações sociais de gênero ${ }^{9}$ não será assim percebida do ponto de vista dos guardiões da ordem institucional. Por outro lado, a cada vez que mulheres políticas buscam manifestar sua solidariedade de gênero para além das clivagens partidárias, seja em palavras ou ações - procurando, por exemplo, constituir grupos femininos na assembleia nacional ${ }^{10}$ - essas práticas são sistematicamente consideradas subversivas pelas organizações partidárias, sob o pretexto de questionarem clivagens políticas pré-estabelecidas (fundadas sobre classe, religião, território, etc.).

A esse respeito, mesmo que a subversão não esteja sempre no que é denunciado, os guardiões da "verdade" também não estão sempre onde se espera que estejam, quer dizer, na instituição na qual ocorrem as práti-

5. NT: No original, intégristes catholiques. Termo por vezes pejorativo atribuído ao movimento conservador que teve lugar na França em oposição às mudanças na Igreja Católica impostas pelo Concílio Vaticano II.

6. NT: No original, Caisses d'allocation familiales.

7. NT: Sigla em francês referente à Caisse Nationale d'Allocations Familiales, órgão responsável pela distribuição de políticas de proteção social. A título de ilustração, o INSS (Instituto Nacional de Seguridade Social) pode ser tomado como um homólogo.

8. Ver Dubois, Buton, Chambolle e Dulong (2003).

9. NT: No original, o emprego da expressão rapports sociaux de sexe (relações sociais do sexo, em tradução literal) ao invés de genre (gênero) remete a divisão biológica masculino/feminino em lugar das questões relacionadas à identidade e expressão de gênero ou orientação sexual. Para fins de tradução, optou-se pelo termo gênero para todos os casos.

10. NT: No original, assemblée nationale. Relativo à Câmara dos Deputados para o caso brasileiro. 
cas etiquetadas como subversivas. Por um lado, porque os atores ocupam com frequência mais de um papel ao mesmo tempo - deputado, prefeito ${ }^{11}$ e membro de partido ou movimento feminista -, de modo que podem ser pegos nas injunções contraditórias de diferentes ordens institucionais às quais pertencem. No caso anterior - aquele dos agrupamentos políticos exclusivamente femininos -, o que seria no máximo uma conduta um pouco banal, até curiosa aos olhos do presidente da assembleia nacional (ou de qualquer outro hemicírculo), é, ao contrário, uma revolta inadmissivel para os partidos políticos que fundaram sua legitimidade sobre a luta de classes (e não dos sexos). Por outro lado, certos papéis são, nas representações existentes, particularmente ligados à ordem social. É o caso, por exemplo, do presidente da República e outras instituições "pontifícias" habilitadas a intervir sobre o que é considerado fundamental, a outorgar uma legitimidade a outros atores, a controlar outras instituições, a arbitrar entre elas, etc. (FRANÇOIS, 1992). Em todos esses casos, a manutenção ou subversão dos papéis pode levar ao engajamento de atores diferentes daqueles que poderiam se beneficiar diretamente. É desse modo que quando o presidente François Mitterrand desce à rua para manifestar, como qualquer outro cidadão, o seu apoio às famílias judias que tiveram seus túmulos profanados, os primeiros a censurarem essa conduta atípica para um presidente são os jornalistas e não seus opositores políticos. É ainda a imprensa que, no início da $\mathrm{V}^{\mathrm{a}}$ República ${ }^{12}$, é a primeira a ordenar que Michel Debré atentasse ao seu papel de chefe do poder executivo diante do presidente da República. E é ainda a imprensa que, transmitindo os ataques da oposição sobre o balanço do sétimo ano de mandato do General De Gaulle, em 1965, constrange-o a sair de seu papel de patriarca apartidário, que ele mesmo se atribuiu, obrigando-o a fazer campanha para o segundo turno da eleição presidencial.

Esse último exemplo nos convida, enfim, a pensar que, da mesma forma que os chamados à ordem, as atividades intencionalmente subversivas talvez não se situem necessariamente no interior da instituiçã $0^{13}$. Por meio das críticas, da autoridade do seu discurso, da mobilização de apoios e de outros meios de pressão, mesmo os atores externos à instituição podem contribuir para subvertê-la.

11. NT: No original, député-maire. A possibilidade de acúmulo de mandatos eletivos (caso do deputado-prefeito) é uma exceção na Europa, contudo, leis restritivas à prática foram aprovadas em 2014 e novas regulamentações propostas em 2019. Disponivel em: <https://www.vie-publique.fr/eclairage/19374-le-cumul-des-mandats-electoraux-une-pratique-de-plus-en-plus-restreinte>; Acesso em: 14/02/2020.

12. NT: Atual período republicano francês, em vigor desde 1958.

13. Se não se trata propriamente de falar em práticas subversivas (dado que não etiquetadas como tal e que colocam em risco apenas o general de Gaulle e não a presidência), pode-se ao menos mostrar que a inscrição da competência econômica nas qualidades requeridas para afiançar o papel de presidente, longe de estar somente ligada à conjuntura econômica dos sete anos de Valéry Giscard d'Estaing, era antes de tudo o produto de uma mobilização coletiva de atores relativamente distantes do espaço político, que buscavam valorizar esse tipo de competência no espaço público. É de fato essa mobilização - iniciada na IVa República, sendo a candidatura de Gaston Deferre na eleição presidencial de 1965 um dos pontos altos que transforma o espaço dos possíveis e do dizível, e permite à Valéry Giscard d'Estaing ocupar sucessivamente as posições de ministro, de candidato e depois presidente da República, sob o estilo inédito de empresário (DULONG, 1997). 


\section{As propriedades do ator}

Esta hipótese é menos negligenciável à medida que os membros da instituição não são sempre os melhores colocados para tentar subvertê-la; até porque a instituição atrai para si os indivíduos que se reconhecem nela e estão, então, predispostos a se conformar às condutas esperadas. Contudo, qualquer pessoa pode ser projetada do dia para a noite no universo institucional do qual ela desconhece os códigos, as regras de funcionamento e os valores. Para esses atores, cuja história de vida é às vezes tão distante da instituição ao ponto dela não poder ser "naturalmente” incorporada, é menos custoso, ou ao menos mais fácil, fazer da necessidade virtude ao reivindicar uma identidade estratégica desviante. É por isso que a entrada dos operários (OFFERLÉ, 1984) ou do grupo poujadiste ${ }^{14}$ (COLLOVALD, 1989) em um ambiente tão burguês quanto a assembleia nacional, ou ainda aquela das mulheres em universos tão masculinos quanto os das instituições política ${ }^{15}$ ou judiciária ${ }^{16}$, são marcadas por condutas profanas, mais ou menos subversivas, mais ou menos aceitas pelos(as) não iniciados(as) em um habitus pouco ortodoxo: uso de vestuário característico (macacão de trabalho ou traje casaco e saia na cor rosa fuchsia da Channel, na assem- bleia nacional), expressão de emoções "impróprias" (as lágrimas de Simone Veil durante os debates sobre o I.V.G. em $19755^{17}$, a raiva dos poujadistes em 1956), desrespeito aos códigos do discurso (usar termos "grosseiros”, tocar em assuntos considerados tabu, ou simplesmente falar "normalmente") e toda outra atitude que manifeste uma certa distância ou insubmissão com relação à ordem institucional.

Para ilustrar esse ponto, tomaremos o exemplo de Malika, educadora de 45 anos, filha de pai operário argelino e de mãe francesa (que teve ao todo nove filhos), eleita em 2004 para o Conseil régional d'T̂le de France (CRIF) ${ }^{18}$ a partir de uma lista de comunistas e candidatos avulsos, depois de uma experiência de vice-prefeita ${ }^{19}$ em Arcueil, nos anos 1980. Sua trajetória improvável é ligada ao contexto de "crise de representação”, que fez de seu handicap social - mulher, de origem magrebina, sem capital escolar e sem nunca ter saído da "cidade" - recurso em um jogo político cada vez mais concorrido.

Ponto positivo pra mim: sou de origem imigrante. Meu pai é bougnoul ${ }^{20}$. Ele era. Por isso era bom nesse momento ter mulheres jovens vindas da imigração (...) Quando ele (o prefeito de saída) me propôs ser vice-prefei-

14. NT: Movimento sindical francês, sob a liderança de Pierre Poujade, em atividade entre 1953 e 1958.

15. Ver Achin et al. (2007).

16. Consultar Boigeol (1996).

17. NT: I.V.G. (Interruption Volontaire de Grossesse), sigla em francês para "interrupção voluntária da gravidez”. Aqui a autora faz referência ao discurso da ministra da saúde nomeada por Jacques Chirac, então primeiro-ministro, em defesa de projeto de lei pela legalização do aborto. Disponível em: <https://madame.lefigaro.fr/societe/discours-le-jour-ou-simone-veil-defendit-ivg-devant-assemblee-dhom-

mes-300617-133051>; Acesso em: 14/02/2020

18. NT: Instituição composta via eleições regionais e encarregada de funções administrativas. A região de Île-de-france representa uma divisão administrativa do Estado francês e exerce jurisdição sobre um território que compreende a capital, Paris.

19. NT: No original, maire-adjointe.

20. NT: Forma por vezes pejorativa em referência a imigrantes de origem magrebina (região norte-africana) 
ta, eu disse pra ele: 'você está louco! Eu nunca vou ser como vocês!' Ele me disse: 'é disso que precisamos'.

Seu percurso é, portanto, característico de um conjunto de ajustamentos difíceis a universos institucionais tão distantes de suas origens sociais e preocupações, que apenas podem ser adaptações secundárias. Assim, não foi por falta de ter testado outros grupos que ela se engajou finalmente no único partido que melhor lhe "corresponde", o P.C.F ${ }^{21}$ :

Aderi novamente ao P.C. porque é a única formação política que tem a ver com alguém como eu. Não poderia ser a extrema esquerda, porque eu já tinha testado os autônomos e ali eu percebi que eram pequenos burgueses, que não tinham muita coisa a ver comigo, exceto os acessos de raiva. Os Verdes, eram a mesma coisa. Com o P.S. ${ }^{22}$ eu não tive contato. A L.C.R. ${ }^{23}$ também não.

Trata-se, contudo, de uma adesão "na falta de algo melhor", o que se reflete na relação distante que ela tem com "o partido": "Eu não me sinto ligada a qualquer pessoa ou organização em particular. Nem ao P.C.F, enfim, e isso não me traz nenhum problema. Ao mesmo tempo, eu reconheço o que a organização me proporcionou”.

Agradecida ao seu partido ela, entretanto, lhe recusa a exclusividade do seu engajamento. Com um pé dentro e outro fora, o partido pede que ela escolha:

Em 95, meu partido - enfim, meu partido... oficial, no qual estou desde sempre, hein! - me pediu pra escolher entre meu mandato como eleita e minha atividade associativa [...]. É óbvio que demorei bastante tempo pra responder. Eu recusei. Eu recusei mesmo estar na lista.

Essa atitude inesperada a relegou a uma posição marginal - o que, afınal de contas, lhe convinha - e se, apesar de tudo, ela é eleita para o CRIF em 2004, é mais devido à paridade de gênero e graças à rede associativa que ela soube criar por fora de qualquer instituição do que por conta da ajuda de sua Federação ${ }^{24}$.

A sua posse como eleita regional dá início a uma nova aventura, que ocorre no descompasso entre o que ela é e as prescrições - também vagas e pouco rígidas desse papel ${ }^{25}$.

21. NT: Partido Comunista Francês.

22. NT: Partido Socialista.

23. NT: Liga Comunista Revolucionária. Partido de orientação comunista, em atuação desde 1974, em 2009 passa à denominação Nouveau Parti anticapitaliste (NPA), Novo Partido Anticapitalista. Disponível em: <https://books.openedition.org/pur/21311> e <https://www.lemonde.fr/politique/article/2009/02/04/ la-lcr-se-dissout-pour-donner-naissance-a-un-parti-plus-large-le-npa_1150524_823448.html>. Acesso em: $14 / 02 / 2020$

24. NT: No original, Fédération. 0 agrupamento de células e setores locais formam uma Federação, instância de organização da militância no interior do PCF. Disponível em: <https://www.pcf.fr/le_pcf> ; acesso em: $17 / 02 / 2020$

25. NT: No original, rôle. Aqui, o emprego do termo "papel" (rôle) ao invés de "cargo" (poste), conquanto soe deslocado na tradução, visa conservar a ideia central do conceito utilizado com frequência na sociologia politica francesa. Para uma definição da noção, ver: LAGROYE, J. Sociologie Politique. Paris: Presses de la Fondation nationale des sciences politiques/Dalloz, 1997. 
É que a gente não fala do mesmo jeito, entende! Teve até uma vez que eu tentei falar como eles [os outros eleitos]. Foi um desastre! [risos]. É isso, a gente não se dá conta, mas aqui também nos colocam verdadeiras barreiras. Quando digo que aprendi a falar, ao mesmo tempo eu também sei falar com todo mundo. Então, eu aprendi a participar das reuniões e a me sentir autorizada a falar do meu jeito, com as minhas diferenças, assim como sou, os meus limites, etc. E o que me impressionou também, e que me impressiona ainda regularmente, é que quando você fala um pouco normal - que merda, eu não sei disfarçar! - tem gente que mete a cabeça nos papéis, ora! Você sabe que deixou as pessoas incomodadas. [...] Quando não entendo, eu digo pra eles [risos], mesmo se isso parece... Quer dizer, tem coisas que me deixam à vontade. A vida é assim mesmo.

Com certeza, esse tipo de comportamento é mais incômodo que perigoso. É, contudo, subversivo pois significa a rejeição de tudo que se atribui ao papel. Mais que isso, o que Malika reivindica através dessa conduta é um outro modo de ocupar a posição, que ela qualifica de "normal”, estigmatizando o vazio do habitus burguês dos seus colegas e, com ele, o mecanismo sobre o qual repousa uma parcela da delegação política:

Eu tenho sorte, vivo fora da minha bolha. Como não tenho dinheiro, estou morando em um H.L.M. ${ }^{26}$ normal, com pessoas que normalmente são um saco, com traficantes que traficam por todo lado e poli- ciais que estão por toda parte, com gente que não está nem aí, que se dão bom dia, que se xingam, quero dizer NORMAL! E todo mundo com as mesmas dificuldades na vida. Por isso que eu provoco as pessoas e preciso muito disso. Porque, na política, se a gente não faz isso, não sei pra quê a gente serve. E acho que isso é um dos problemas desse meio. Você pode passar o tempo todo em reunião, pode ter a agenda sempre cheia. Isso serve pra quê?! Assim, as reuniões são importantes, claro, o problema não é esse. É por isso que estou dizendo que a gente tem um verdadeiro problema. Temos um problema de relação com o tempo, de relação com as pessoas. (Entrevista realizada no CRIF, dia 13 de maio de 2005)

Ao lado dessa categoria de atores "subversivos", aqueles que ocupam em maior medida as posições marginais na instituição - ou no espaço social onde essas atividades ocorrem - são também mais dispostos que outros a comportamentos desviantes. $\mathrm{Na}$ teoria dos campos, Pierre Bourdieu explica, na realidade, que, nesse espaço estruturado de posições estruturantes, os dominados oferecem um ponto de vista sobre o campo menos encantado que os dominantes, o que favorece, assim, comportamentos mais subversivos. Além disso, os exemplos desse tipo não faltam, da história da universidade àquela das organizações partidárias ou sindicais, nos quais é possível observar que as tentativas de subversão são principalmente um traço dos "subalternos" (BOURDIEU, 1984), dos "jovens turcos"27, dos “coadju-

26. NT: Sigla em francês para Habitation à Loyer Modéré (habitação por aluguel de baixo custo). Trata-se de imóveis alugados sob subvenção do Estado à população de baixa renda.

27. 0 exemplo mais conhecido é, com certeza, o dos "jovens turcos” do partido radical. Mas a criação do RPR, através do qual Jacques Chirac marginaliza os barões do gaullisme, é também analisado por essa perspectiva. Ver Offerlé (1983) e Gaxie (1977). 
vantes"28 $29 \mathrm{e} / \mathrm{ou}$ grupos minoritários ${ }^{30}$. A história da administração mostra, da mesma maneira, que as lutas no interior do Estado são, de modo indissociável, uma disputa pela sua definição e lutas pelo poder entre insiders e outsiders. De modo geral, e como mostrou Haroun Jamous sobre os médicos (1969), Pierre Muller sobre os sindicalistas camponeses (1989), ou mais recentemente Antoine Vauchez sobre a magistratura italiana (2004), grande parte das reformas que se inserem em determinados contextos sociais são, ao menos em parte, produto da atividade subversiva de "marginais-transversais" ${ }^{31}$ que buscam, principalmente, redefinir os papéis sociais que lhe são atribuídos.

Contudo, não se deve deduzir que a subversão seja apenas o ato de agentes socialmente dominados. Pelo contrário, do normalista $^{32}$ Tardieu $^{33}$ (que recusa se do- brar às expectativas dos deputados ao tomar posse na presidência do Conselho ${ }^{34}$ em novembro de $1929^{35}$ ) ao presidente de Gaulle (que exerce uma prática no mínimo ampliada das suas prerrogativas constitucionais), não faltam exemplos de atores dominantes, tendo todas as pré-disposições para se conformar de modo quase "natural" ao seu papel institucional, mas que preferem, por razões às vezes ideológicas e estratégicas, atuar sob um registro desviante, colocando em perigo as instituições que encarnam. Esses exemplos, como a figura emblemática do "Che" e de muitos outros revolucionários vindos, como ele, de meios sociais mais favorecidos, nos convidam a pensar que se a predisposição em desviar dos comportamentos esperados não é igualmente distribuída na sociedade, a capacidade de fazê-lo também não é. Pa-

28. Consultar principalmente Bernard Pudal (1989). 0 autor mostra que aqueles que deixam a SFIO [NT: Seção Francesa da Internacional Operária] são os menos dotados de capital cultural e político.

29. NT: No original, "seconds couteaux". Trata-se de idiomatismo usualmente referente ao papel subalterno em uma atividade criminosa, nesse caso a expressão foi usada no sentido figurado.

30. Diversos exemplos podem ser encontrados em Dulong (1997).

31. A expressão é de Haroun Jamous e designa os atores que ocupam uma posição não central no seu setor de atividade, mas que compensa esse "handicap" graças à ajuda externa que adquirem a partir da diversificação das atividades fora do seu setor. Atores marginais mas multi-posicionais, eles se encontram na intersecção de vários campos e são assim mais inclinados que outros a ter uma visão heterodoxa.

32. NT: No original, normalien. A expressão faz referência à passagem pela École Normale Superieure, prestigiada instituição de ensino superior.

33. NT: Tardieu foi presidente do Conselho de Estado em 1929.

34. NT: Referência ao Conselho de Estado Francês, instância responsável por julgar atos administrativos, elaborar pareceres sobre propostas de lei e elaborar diretrizes para a ação do Estado. Disponível em: <https://www.conseil-etat.fr/>. Acesso em: 18/02/2020.

35. Ele se recusa, de modo simbólico, a consultar os grupos parlamentares sobre a composição do seu gabinete. Depois, na ocasião da sua declaração ministerial, em lugar de anunciar grandes ideias gerais a fim de conquistar a adesão do máximo de deputados às suas políticas, Jean Tardieu fala como um homem de negócios, citando de forma seca, toda uma série de dados. Esse estilo novo, percebido como uma verdadeira provocação, choca ainda mais quando Tardieu multiplica as viagens ao interior para explicar à opinião pública seu programa e quando, rompendo com a tradição da neutralidade do governo, comporta-se como verdadeiro chefe da maioria, tomando a frente da campanha eleitoral de 1932 e se dirigindo à toda França através do rádio. 
ra ser mais precisa, as práticas subversivas podem ser em maior medida “jogáveis” por quem detém recursos suficientes para suportar os riscos e os custos ${ }^{36}$.

De fato, por não se estar nem verdadeiramente no papel nem completamente estranho a ele, quando se está na instituição com um pé fora dela, os comportamentos desviantes e $a$ fortiori subversivos não são fáceis de manter: além das eventuais sanções materiais e/ou simbólicas que provocam (retornaremos a este ponto), esses comportamentos são em si psicologicamente custosos. A sociologia, com frequência, evita levar em conta esse tipo de consideração. Mas basta observar novos ingressantes adotarem pela primeira vez um papel institucional para se convencer que esses custos psicológicos pesam demasiado sobre o comportamento dos atores institucionais. Esses últimos, em geral, têm apenas uma vontade: se integrar, se conformar ao papel, se curvar aos seus constrangimentos para evitar a reprovação coletiva, obter o reconhecimento dos pares e da hierarquia, até o ponto em que uma boa parte de sua atividade estratégica consista - ao menos na fase de aprendizado - na busca por antecipar as eventuais sanções que podem vir a ocorrer. Compreende-se, portanto, porque as sanções ofıciais (excomunhão, demissão, deposição, etc.) são na prática raramente executadas: além do fato de revelarem a fragilidade real da instituição (não sendo utilizadas senão como último recurso), elas agem, sobretudo, de maneira indireta e in- visível enquanto constrangimento internalizado pelo atores ${ }^{37}$. Como escreveu Anthony Giddens: "as propriedade estruturais dos sistemas sociais não agem sobre uma pessoa” como se fossem exteriores, mas estão implicadas $n a$ conduta dos atores, sob a forma de um autocontrole mais ou menos (bem) vivido como tal (GIDDENS, 1987, p. 239). Assim, como admite Malika, ela no início "tentou ser como" os outros eleitos. Mesmo os deputados da Frente Nacional ${ }^{38}$ em 198688, que fizeram da subversão a marca de seu grupo na assembleia, buscaram a legitimidade desde o início do mandato (BIRENBAUM, 1992). Quanto aos atores cujo habitus é estranho às normas institucionais, esses vivem geralmente mal a sua marginalidade, mesmo que reivindicando essa distância em relação à instituição.

Apesar de ressaltar uma distância crítica em relação ao CRIF ou ao PCF, a entrevista com Malika revela os limites do habitus do dominado no que tange ao fenômeno das práticas e condutas subversivas. Essa entrevista, na verdade, foi a ocasião para que ela expressasse todo o sofrimento que tem suportado depois de um ano de mandato: "os primeiros momentos aqui foram terríveis! Foram terriveis!", "Nunca vi tanto desprezo por metro quadrado". Essa "boca grande” não tem, por exemplo, palavras suficientemente fortes para contar a provação por que passou na primeira vez que tomou a palavra em público: "Eu fiquei aterrorizada, porque é impressionante. É muito

36. Para verificar essa hipótese, é preciso observar principalmente as trajetórias posteriores dos atores subversivos.

37. A eficácia das sanções reside menos na sua utilização que no simples fato de existir.

38. NT: No original, Front National. Partido fundado em 1972 a partir de uma tendênia moderada no interior da extrema direita francesa (KAUFFMAN), mudou sua denominação para Rassemblement National em 2018. Disponivel em: <https://www.theguardian.com/world/2018/jun/01/marine-le-pen-rebrands-front-national-in-push-for-support>. Acesso em: 18/02/2020. Para uma referência sobre as origens do Front National, consultar KAUFFMAN, G. Les origines du Front National. Politix, n.157, 2016/2, p.5-15. 
impressionante! Isso me dá mais medo do que a prisão de Fresnes" ${ }^{39}$. Dentro da instituição, deve-se encarar o medo, o estresse, a vergonha diante do "mal-estar" dos colegas ou ainda a "má reputação" ("Eu não estou nem aí. Não estou...”). Contudo, do lado de fora da instituição, deve-se ainda encarar os sarcasmos da família: "Na minha família, eu sou uma excêntrica! Em casa a gente é tudo trabalhador! [imitando os familiares ironizando sua situação]: "Você foi eleita? Isso serve pra quê? Essa gente trabalha?"

Não tão fácil, portanto, fazer da necessidade virtude... Considerados os custos relativos às práticas e condutas subversivas, compreende-se então que estas são, de fato, menos a marca dos dominados que de atores de habitus clivado, igualmente predispostos, mas mais aptos, sem dúvida, a incorporar esse tipo de posição ambivalente por tê-la incorporado muito cedo. Mesmo dominada, Malika ocupa uma posição no CRIF, mas se ela "resiste" é porque, como ela diz, ela "é apenas isso": filha de imigrante, ela se sente antes de tudo francesa, o que ela é por parte de mãe.
Então, para mim isso foi sempre um pouco complicado, porque eu vim da imigração, mas minha mãe é francesa. Como eu sempre digo, minha avó, ela era de Choisy-le-Roi e também tenho um parente distante que morreu na Comuna de Paris... e depois outros em Sétif ${ }^{40}$ [risos]. Isso é muito engraçado. Mas, ao mesmo tempo, eu me deparo com o racismo desde sempre. Então, no início dos anos 80 , era bem visto apresentar jovens, vindos de... bla-bla-bla. Apesar de que eu não era nada além de jovem e ‘vinda de...'. Eu ainda sou eu mesma.

Compreende-se ao mesmo tempo que as práticas desviantes são o produto de uma illusio $^{41}$ paradoxal, pois vivida de modo desencantado - quando as práticas não visam mudar a instituição - ou de modo inocente - à medida que elas visam a mudança mas por meio de um ajuste das estruturas às disposições do ator. Ora, é aqui que a força da instituição se faz sentir com mais intensidade: na sua mais ou menos forte capacidade para controlar a illusio dos seus membros ${ }^{42}$.

39. NT: Centro penitenciário localizado na cidade de Fresnes (Île-de-France), em funcionamento desde 1898. Disponível em: <https://oip.org/etablissement/centre-penitentiaire-de-fresnes/> Acesso em: $19 / 02 / 2020$

40. NT: Cidade no nordeste da Argélia, palco de violenta repressão do governo francês contra os movimentos de independência em 1945. 0 episódio ficou conhecido como "Massacres de Sétif, Guelma e Kherrata". 41. Por illusio, entende-se, conforme Pierre Bourdieu, "essa relação encantada à uma disputa que é produto de uma relação de cumplicidade ontológica entre as estruturas mentais e as estruturas objetivas do espaço social” (BOURDIEU, 1994, p.151).

42. A esse respeito, se Malika resiste tanto bem quanto mal no CRIF - em todos os sentidos - é porque pouco ela tem da illusio (“eu não tinha ilusões. Tenho ainda menos, hoje. E isso fortalece a minha postura na política”) e por ter vivido uma experiência “deslocada”, longe de romper, fortalece sua crença na necessidade de engajamento contra as desigualdades sociais: "Que merda, a gente precisa fazer eles compreenderem que a sua vida - mas sabe, quando eu digo 'sua' eu me deixo de fora, eu não tenho a mesma vida que Huchon, não tenho a mesma vida que muita gente, mesmo aqui, mesmo no meu grupo, é preciso que me expliquem porque, isso não é normal! Eu não tenho o mesmo acesso às férias, não tenho o mesmo acesso ao lazer, etc. É preciso que me expliquem. Por quê? Por quê? Não. Isso não vai me fazer desistir. Isso me deixa com mais raiva ainda”. 


\section{As propriedades da instituição}

Os comportamentos subversivos dependem igualmente das propriedades da instituição. Algumas, como as burocracias administrativas, não têm outra pretensão senão a de reduzir seus membros ao papel de simples agentes de execução. Em tais contextos, os atores têm como únicas prescrições aplicar um dado número de regras gerais e impessoais, reprimindo tudo o que é da ordem da individualidade. Além desse constrangimento, seu papel é, na maior parte do tempo, objeto de definição vaga e incerta, e seu comportamento é fracamente controlado - de modo que as práticas e condutas desviantes ocorrem com mais facilidade quanto menos comprometerem a instituição ${ }^{43}$. Sendo os primeiros e mais numerosos a terem estudado a "desobediência nos recursos humanos" ${ }^{44}$, os trabalhos de sociologia das organizações administrativas mostram que essa forma de desobediência é inerente a esse tipo de organização ${ }^{45}$. Ao contrário, outras instituições buscam exercer um forte controle sobre o comportamento de seus membros. É o caso das famosas instituições "totais" como as prisões, os conventos, o exército, etc. Mas é também o caso dos partidos políticos que, desde a profissionalização da atividade política e a acentuada concorrência entre si, têm desenvolvido dispositivos práticos e simbólicos de controle dos atores que compensam largamente a falta de codificação propriamente jurídica das regras e dos papéis que devem seguir.

Entre esses dispositivos de controle, aqueles referentes à entrada na profissão são, de longe, os mais eficazes. Sem poder garantir, eles permitem um relativo ajuste dos outsiders às expectativas dos insiders. Antes mesmo da adesão, os dirigentes partidários podem, por um sistema de apadrinhamento mais ou menos formal, controlar a inscrição do futuro filiado em uma rede de sociabilidade conhecida e se precaver contra qualquer perfil fora do padrão ${ }^{46}$. Por intermédio das organizações de "juventude", os partidos políticos podem inculcar nos futuros filiados as regras tácitas do jogo político e socializá-los nas expectativas concernentes aos papéis políticos que ocuparão - como construir um discurso político internamente, adaptá-lo a um público externo, garantir a segurança em uma manifestação, etc. (YON, 2003; BARGEL, 2008). Nesse sentido, os mais jovens, os quais podemos encarar como estando em maior distância em relação à ordem estabelecida do que seus veteranos, são, na verdade, os mais profissionais dos militantes, e, portanto, os mais "dóceis" - ao menos nos casos dos que pretendem uma carreira política. Isso porque, já em parte formatados pelas organizações de juventude, seu potencial subversivo

43. Para um exemplo particularmente estimulante, ver Dubois (2003).

44. Essa famosa expressão de Philip Selznick (1949) designa a autonomia relativa que os atores conservam com relação à regras e às estruturas nas quais estão inseridos, autonomia que toma com frequência a forma de uma resistência individual às injunções dos superiores, mas que pode levar à uma ação coletiva mais subversiva.

45. Por não ser possível citar todos aqui, nos remetemos à análise crítica de Friedberg (1993).

46. Posteriormente, um sistema de biografias permite gerenciar o perfil dos quadros de filiados. Ver Pudal e Pennetier (2002). Contudo, esse sistema não existe apenas nos partidos. Consultar, por exemplo, Agrikoliansky (1994). 
é tanto mais neutralizado quanto mais acirrada for a concorrência interna pelo acesso às posições de poder, o que justifica a existência de dispositivos de regulação da concorrência - que são, na realidade, apenas um meio de controle mais eficaz.

0 exemplo da entrada massiva de mulheres na vida política, em razão da lei que introduziu a paridade homens/mulheres, é aqui particularmente esclarecedor. Por ter de garantir uma melhor representação política das mulheres e pelo fato de serem conhecidas por fazer política de outro modo - ou seja, mais "próximas" das pessoas, mais "compreensivas", menos "carreiristas" etc. -, essa lei deveria também, para muitos, permitir uma renovação das práticas políticas. Entretanto, a revolução não ocorreu, uma vez que os efeitos potencialmente mais subversivos dessa renovação de pessoal foram em grande parte neutralizados precocemente, no momento das investiduras (ACHIN et. al., 2007). De fato, via meios associativos, laços de amizades ou mesmo fa- miliares, mais que por intermédio dos partidos, recrutando mais professoras primárias do que empresárias, selecionando candidatas mais a partir de seus atributos pessoais (idade, origem étnica, etc.) do que a partir de suas redes, enfim, escolhendo mulheres segundo critérios específicos de seu gênero, os responsáveis pelas listas descartaram mulheres já engajadas na competição e bem inseridas nas redes militantes em benefício de um perfil de candidatas mais conforme às suas expectativas: mulheres "profanas", de competências "femininas" e pouco interessadas pela carreira política. Esse recrutamento - que expõe as expectativas impostas às mulheres na política - tem em grande parte aliviado a carga subversiva da entrada de mulheres na política, limitando suas chances de fazer carreira e/ou excluindo as mais "perigosas" (como as militantes mais experientes e as feministas). Quanto àquelas que conseguiram passar pelos filtros, ou que descobrem uma ambição política no meio do caminho, devem, em seguida,

Não há quase nenhuma produção acadêmica sobre as condutas e práticas subversivas "femininas" nas instituições “masculinas". Os trabalhos anglo-saxões, de longe os mais ricos na questão de gênero, dedicam-se sobretudo à exclusão das mulheres e, quando saem dessa rotina, se questionam menos sobre o que as mulheres devem às instituições do que as instituições devem ao gênero. Os trabalhos mais interessantes a esse respeito mostram que as instituições têm gênero - ou seja, que elas participam da construção social do feminino e do masculino - e que o gênero, que não é uma coisa mas uma relação, se refaz permanentemente... com resultados quase sempre nulos sobre a subversão da dominação masculina ${ }^{47}$. Certamente, a simples presença de um número importante de mulheres em uma instituição "masculina" é em si subversiva ao menos por duas razões: de um lado, põe em risco a definição masculina assegurada pela instituição; por outro lado, tende a desvalorizar a instituição à medida que atribui-se ao gênero feminino um valor negativo ${ }^{48}$. De todo modo - e evidentemente conectado -, a

\section{Ver West e Zimmerman (1987) e Kenney (1996).}

48. Sobre esse ponto, consultar os trabalhos de Françoise Héritier que mostram que o gênero não é um marcador apenas da identidade pelo sexo dos seres e das coisas, mas também, e de modo indissociável, do valor que lhe é socialmente atribuído. 
literatura sobre a entrada de mulheres nas profissões "masculinas" mostra que os dispositivos de controle são suficientemente numerosos para neutralizar o risco, mesmo quando as mulheres estão em igual número que os homens. Na pior das hipóteses, a instituição é desvalorizada pela feminização e os homens a abandonam e deixam de cobiçá-la... Assim, e contrariamente à célebre teoria de Rosbeth M. Kanter - segundo a qual a proporção de mulheres em um grupo instituído deve ultrapassar ao menos 15\% para que não sofram discriminação e possam imprimir a sua marca -, apenas a força do número não basta para compensar o handicap das minorias estigmatizada ${ }^{49}$. Isso pode ser observado em universos altamente concorridos e profissionalizados - que são, também e na maior parte, feudos masculinos - como mostra, de modo emblemático, o caso da implantação da lei sobre a paridade homens/mulheres na política. Contudo, a questão permanece posta a respeito dos setores mais abertos (e portanto menos masculinos), quanto mais complexos forem os mecanismos de recomposição das relações sociais postos em prática ${ }^{50}$.

encarar um outro tipo de provação. Aos dispositivos que visam controlar a entrada na profissão, juntam-se aqueles que permitem o controle das lealdades, principalmente via regulação de carreiras. Por intermédio das promoções internas, investiduras, alocação de recursos individuais ou outras formas de gratificações, os dirigentes mantêm a crença dos membros no funcionamento virtuoso da instituição. Por meio da suspensão de tais gratificações, da reprovação coletiva, do ostracismo e de toda outra forma de sanções morais ou materiais, incita-se com mais frequência à defecção que à subversão. Assim, por ter revelado em livro uma outra verdade sobre a instituição, aquela das cozinhas e dependências dos membros do Partido Socialista de Bordeaux, uma militante socialista, que havia tido uma votação histórica nas eleições legislativas de 2002, viu sua candidatura ser retirada nas eleições seguintes. Como tinha em aberto outros espa- ços de atuação, ela passou a considerar que não valia a pena e deixou de investir no jogo político. Uma outra, conselheira municipal em uma cidade média, cujas ações e discursos incontroláveis foram transmitidos pela mídia, teve sua vida privada publicamente difamada. Como ela se beneficiava de uma notoriedade pessoal, deixou o conselho municipal para tentar a sorte no nível nacional. Quanto àqueles/as numerosas/os, que formaram as listas dissidentes na véspera das primeiras eleições paritárias, rapidamente renunciaram à sucessão depois de ter obtido compensações satisfatórias (promoções internas, candidaturas nas eleições legislativas seguintes, etc.).

Isso significa dizer que, em um espaço como esse, rígido e de acirrada concorrência, é raro fazer uma "carreira" desviante e, a fortiori, subversiva. Além disso, as práticas e condutas mais "perigosas", frequentemente não são senão disputas pela honra

49. Ver Kanter (1977); e para uma crítica fundamentada em trabalhos empíricos, ver Yoder (1991). 50. Ver Kergoat e Vilbrod (2008). 
entre aqueles que, não tendo nada a perder, estão prontos para desertar. Exceto que, à maneira dos intelectuais comunistas e suas práticas de contrabando - que são apenas uma das marcas "do poder, do símbolo do seu respeito e uma maneira de trapacear" (MATONTI, 2005, p.15) -, as atividades desviantes permaneçam suficientemente discretas e toleráveis aos olhos daqueles com poder de sancioná-las. Dito de outra forma - aquela de Goffman -, trata-se frequentemente de "adaptações integradas" (que não visam a subversão da ordem estabelecida) ou condutas de distanciamento que manifestam uma recusa em ser o que a instituição espera que sejamos sob uma forma dissimulada (como a ironia, absenteísmo, resistência passiva etc.) (Ibid. , p. 243 em diante). Em todos os casos, as condutas desviantes não são, enfım, tão perigosas para a instituição quanto as "adaptações integradas”. Mais do que isso, elas se revelam, pela análise do seu contexto de produção, frequentemente mais funcionais que perigosas.

\section{As propriedades da situação}

Quer estejamos dentro ou fora da instituição, a passagem para a ação subversiva não ocorre em qualquer contexto. Algumas situações são de fato mais propícias que outras. Trata-se aqui muito particularmente das conjunturas fluidas de ruptura com as rotinas institucionais como as crises ou mudanças de regime (DOBRY, 1992 [1986]). Nesse tipo de contexto, os custos individuais da subversão diminuem pela incerteza que pesa sobre as normas e seu futuro, o relaxamento dos dispositivos de coerção, a dispersão da autoridade ou ainda a invasão de novos atores nas instituições. Com efeito, a invasão de mulheres na política não pode ser compreendida independentemente de um contexto de crise da representação política e, mais precisamente, das vocações municipais. 0 ingresso dos intelectuais no interior do comitê central do PCF, até então operário, é similarmente ligado ao contexto do aggioramento posterior à morte de Stálin; do mesmo modo, a crise dos operários na assembleia nacional ocorre após primeira e Segunda Guerra Mundial, etc. A cada vez, a análise desse ambiente exterior esclarece as motivações dos atores e as transações que operam na instituição. Mais que isso, ela nos permite frequentemente observar os comportamentos subversivos sob uma perspectiva tão inusitada quanto paradoxal: aquela dos usos políticos e sociais da subversão pelos próprios guardiões da instituição.

De fato, nesses contextos particulares é com frequência a instituição, ou ao menos os seus dirigentes, que atribuem a alguns de seus elementos um papel subversivo. 0 caso da invasão de elementos femininos supostamente subversivos no campo das instituições políticas é, mais uma vez, exemplar. Primeiro porque essa subversão é organizada pelos legisladores nos termos de uma aliança entre alguns movimentos feministas (os menos radicais) e o governo da esquerda plural, dirigido por Lionel Jospin; em seguida porque, como explica o primeiro ministro aos parlamentares reunidos em um congresso em 2000, essa subversão legalizada não visa colocar as instituições em perigo ${ }^{51}$, muito pelo contrário: é "para que nossa democracia, profundamente renovada pela feminização, ganhe em dinamismo, em vitalidade, em imaginação”. Compreende-se as-

51. Mesmo que uma das consequências da paridade seja prejudicar as lealdades partidárias, bagunçando as retribuições do militantismo. 
sim que: as práticas subversivas esperadas, mais que isso, impostas às mulheres, longe de serem consideradas como perigosas por todos os guardiões da democracia, são pensadas como funcionais e mesmo vitais. Esse tipo de uso da subversão se inscreve, então, nas estratégias de remotivação que, assim fazendo, mantêm a illusio de seus membros e os impedem, pelo rito e pela crença reacesa, de sucumbir à desmotivação que sempre corre o risco de acompanhar a institucionalização (HERAN, 1987).

Quer se pesquise ou não, essa dimensão funcional das práticas desviantes é bem mais presente do que se imagina. É assim, por exemplo, que as práticas de contrabando de intelectuais comunistas da Nouvelle Critique permitiram ao partido operar uma reviravolta delicada de desestalinização, teorizando a mudança e recuperando o sentido da doxa comunista. Em alguns casos, os dirigentes se apoiam sobre esses desvios da regra para justificar uma reforma institucional (CAHTY, 1997). Quando, por sua vez, François Mitterrand (ao participar de uma manifestação de rua), Valéry Giscard d'Estaing (tocando acordeão) ou ainda Nicolas Sarkozy (vestido em trajes de jogging) saem publicamente de seu papel presidencial, o que manifestam, além do distanciamento desse papel, é a "humanidade da grandeza”, ou seja, a humanidade compartilhada com aqueles sobre os quais exercem seu poder (DULONG, 1994)52. Por intermédio desses comportamentos inesperados, é garantida a possibilidade de um ajustamento entre os meros mortais e a ocupação de uma posição de grandeza, apagando e ao mesmo tempo preservando a fronteira entre o poder e seus súditos, entre o sagrado e o profano, trabalhando pela legitimação da instituição.

Contudo, as práticas e condutas desviantes podem de todo modo ser construtivas à medida que não são controladas nem orquestradas pelos dirigentes. Quando demandam uma sanção, são acompanhadas geralmente de discursos de remotivação e às vezes até mesmo de cerimônias de renovatio (assembleia geral extraordinária, votação interna, etc.) através das quais a instituição se esforça em:

renovar a ordem social, seus princípios de classificação e suas finalidades declaradas, proclamando ao mesmo tempo sua própria necessidade, sua insubstituível função, do mesmo modo que sua capacidade em garantir o bom funcionamento das relações sociais

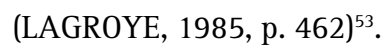

Quando são dissimuladas, quando não provocam a reprovação coletiva ou mesmo quando são toleradas por aqueles que têm o poder de sancioná-las, elas permitem aos seus autores uma integração mínima, seja por terem a ilusão de frustrar o peso que a instituição busca exercer sobre si, seja porque, mesmo diferentes, deduzam que, como Malika, têm todos cada um o seu lugar na instituição - e o sentido de adaptação secundária faz aqui todo sentido. Em certos casos, essas adaptações secundárias são tão mais toleradas pela hierarquia à medida que - à semelhança dos agentes de controle que violam o código de ética da CNAF, ou mais amplamente do pessoal administrativo que investe e personaliza a relação agente/ administrado quando deveria permanecer neutro e anônimo (DUBOIS, 2003) - participam do bom funcionamento da institui- 
ção, humanizando-a ou obtendo pelas práticas oficialmente proibidas o que as prescrições formais não permitem alcançar. Enfim, quando conseguem se impor apesar da hierarquia e das sanções ao ponto de finalmente aparecerem como novas práticas legitimas, contribuem para regenerar a instituição e a consolidam sob o preço de algumas renovações de sentido.

0 estudo de Antoine Vauchez sobre a justiça italiana é, sobre esse último ponto, esclarecedor. De um lado, por descrever como os magistrados antiterroristas, situados na posição mais baixa da hierarquia profissional, nas fronteiras do território italiano e em um contexto geral de questionamento da preeminência do princípio hierárquico no interior da instituição judiciária, passam a impor suas práticas heterodoxas de interrogatório como fundamento de um novo modelo de excelência profissional. De outro lado, e à medida que essa "empreitada do judiciário" é acompanhada de um trabalho de legitimação que passa principalmente por uma redefinição das relações entre justiça e política, descobre-se como essa tentativa bem sucedida de subversão contribui para remotivar a instituição judiciária, fazendo nascer a crença na sua capacidade renovada em ser a garantidora da integridade do Estado face às diversas ameaças que pesam sobre si.

Inerentes à instituição, as práticas desviantes e mesmo subversivas não são, portanto, necessariamente "desintegradoras". Sem cair em um raciocínio funcionalista, pode-se afırmar que, se elas põem em perigo, contribuem também para consolidá-la. Por estar situada na articulação entre "o instituído e o renovado", elas se inscrevem nas mobilizações em torno da "verdade" da instituição que são, de certo modo, conflituosas mas que, perturbando as rotinas ins- titucionais e reatualizado o sentido de suas regras, produzem o reencantamento da crença na instituição e impedem que se conheça o mesmo destino que a Bela Adormecida: tornar-se inanimada, esvaziada de toda illusio, habitada por indivíduos que nem mesmo esperam ser acordados.

\section{Referências}

ACHIN, C. et al. Sexes, genre et politique. Paris: Economica, 2007.

AGRIKOLIANSKY, E. Biographies d'institution et mise en scène de l'intellectuel. Les candidat au comité central de la L.D.H. Politix, 27, p. 94-110, 1994.

BARGEL, L. Aux avante-postes. La socialisation au métier politique das deus organisations de jeunesse de partis. Jeunes populares (U.M.P.) et Mouvement de jeunesses socialistas (P.S.), Thèse pour le doctorat en scence politique. Paris: Université Paris 1, 2008.

BECKER, H. Outsiders: études de sociologie de la déviance. Paris: Métailié, 1985.

BIRENBAUM, G. Le Front National à l'Assemblée (1986-1988). Respect et subversion de la règle du jeu parlementaire. Politix, 20, p.99-118, 1992.

BOURDIEU, P. Homo academicus, Paris, Minuit, 1984.

BOURDIEU, P. Raisons Pratiques, Paris, Le Seuil, 1994.

CHATY, L. L'administration face au management. Projets de service et centres de responsabilité dans l'administration française. Paris: L'Harmattan, 1997.

COLLOVALD, A. Le poujadisme ou l'échec en politique. Revue d'Histoire moderne et contemporaine, 36 (1), p. 113-133, 1989.

DOBRY, M. Sociologie des crises politiques. La dynamique des mobilisations multisectorielles. Paris: Presses de la FNSP, 1992 [1986]. 
DORLIN, E. La matrice de la race. Généalogie sexuelle et coloniale de la nation française, Paris: La Découverte, 2006.

DUBOIS, V. La via au guichet: relation administrative et traitement de la misère. Paris: Economica, 2003.

DUBOIS, V. et al. Les conditions sociales de la rigueur juridique. La politique de contrôle et de lutte contre la fraude aux prestation sociales à la CNAF et dans les CAF. Dossiers d'études, $n^{\circ} 48$ septembre, p. 1-144, 2003.

DULONG, D. Mourir en politique: l'objectivation des rôles politiques dans les éloges funèbres. Revue française de science politique, 44 (4), p. 629646, 1994.

DULONG, D. Moderniser la politique. Aux origines de la Ve République. Paris: L'Harmattan, 1997.

DULONG, D. Des actes d'institutions d'un genre particulier. Les conditions de légitimation des femmes sur la scène électorale (1945 et 2001). In: LAGROYE, J. (Org.). La politisation. Paris: Belin, 2003, p. 425-443.

FRANÇOIS, B. Le president pontife constitutionnel. Charisme d'institution et construction juridique du politique. In: LACROIX, B.; LAGROYE, J. (Orgs.), Le président de la République. Usages et genèses d'une institution. Paris: Presses de la FNSP, 1992, p. 303-331.

FIEDBERG, E. Le pouvoir et la règle. Dynamique de l'action organisée. Paris: Seuil, 1993.

HEINICH, N. La gloire de Van Gogh: essai d'anthropologie de l'admiration. Paris: Minuit, 1991.

HÉRAN, F. L'institution démotivée: de Fustel de Coulanges à Durkheim et au-delà. Revue Française de sociologie, 28, p.67-97, 1987.

GAXIE, D. Économie des partis et rétributions du militantisme. Revue Française de Science Politique, 27 (1), p. 123-154, 1977.

GIDDENS, A. La constitution de la société: éléments de la théorie de la structuration. Paris: PUF, 1987.
GINZBURG, C. Le sabbat des sorcières. Paris: Gallimard, 1993.

GOFFMAN, E. Asiles. Études sur la condition sociale des maladies mentaux et autres reclus. Paris: Minuit, 1968 [1961].

GUICHARD-CLAUDIC, JY.; Kergoat, D. ; Vilbrod A. (Orgs.), L'inversion du genre: quand les métiers masculins se conjuguent au féminin... et réciproquement. Rennes: Presse Universitaires de Rennes, 2008.

KANTER, R. M. Men and Women of the corporation. New York: Basic Books, 1977.

KENNEY, S. J. New Research on Gendered Political Institution. Political Research Quaterly, 49 (2), p. 445-466, 1996.

LAGROYE, B. La légitimation. In: GRAWITZ, M.; LECA, J. (Orgs.). Traité de science politique, vol. I, Paris: PUF, 1985, p. 395-467.

MATONTI, F. Intellectuels communistes: essai sur l'obéissance politique. La nouvelle critique (19671980). Paris: La Découverte, 2005.

MUCHEMBLED, R. La sorcière au village (XVeXVIIIe siècle). Paris: Gallimard, 1979.

OFFERLÉ, M. Transformation d'une entreprise politique: de l'U.D.R. au R.P.R. (1973-1977). Pouvoirs, 28, p. 5-26, 1983.

PUDAL, B; PENNETIER, C. (Orgs.), Autobiographies, autocritiques, aveux dans le monde communiste. Paris: Belin, 2002.

SELZNICK, P. The TVA and the Grass Roots. New York: Harper Torchbook, 1966 [1949].

WEST, C.; ZIMMERMMAN, D.H. Doing gender. Gender and society, 1(2), p. 125-151, 1987.

YODER, D. Rethinking Tokenism: Looking beyond Numbers. Gender and Society, 5(2), p. 178-192, 1991.

YON, K. L'incorporation de l'autorité social chez les militants du Bureau national de l'UNEF-ID. Production et reproduction d'une "elite militante". Cahiers du Germe, 4, p.89-107, 2003. 
RESUMO

0 artigo aborda a noção de instituição retomando as diferentes dimensões de análise implicadas no estudo de práticas e condutas subversivas. Apresenta uma reflexão sobre esses comportamento e sua vinculação, por um lado, com mecanismos de censura ou validação (regras e papeis institucionais), e, por outro, com as propriedades dos atores, da própria instituição e do contexto, com especial foco na presença de mulheres em espaços políticos.

\section{PALAVRAS-CHAVE}

Instituição. Práticas e Condutas Subversivas. Papéis e Regras.

\section{ABSTRACT}

The article addresses the notion of institution by taking up the different dimensions of analysis involved in the study of subversive practices and conducts. It presents a reflection on these behaviors and its connection, from one side, with censorship or validation mechanisms (rules and institutional roles), and on the other, with the properties of the actors, the institution itself and the context, with special focus on the women's presence in political spaces.

\section{KEY-WORDS}

Institution. Practices and Subversive Conducts. Roles and Rules. 
